\title{
Um truque com cartas usando a base numérica 3
}

\author{
Miguel V. S. Frasson(1) Lee Y. Sheng(D)
}

\begin{abstract}
Resumo
Com habilidade em representar números na base 3, um mágico pode executar um impressionante truque com cartas apresentado neste trabalho.
\end{abstract}

Palavras-chave: Base numérica três; truque de mágica; cartas.

\begin{abstract}
With the ability to represent numbers in base 3 , a magician can perform a spectacular card trick revealed in this work.

Keywords: Number base three; magic trick; cards.

\section{Introdução}

A mágica sempre encantou o homem, mesmo os truques simples. Entre tantos truques, há os que se baseiam em conceitos matemáticos, os quais podem despertar o interesse pela Matemática uma vez que o truque seja embasado matematicamente $[1,2]$. Entre os truques que têm conceitos matemáticos estão o truque do "número pensado" [3], "do calendário" [4], aqueles que usam cartas/baralho [5, 6], entre vários outros [4, 7].

Apresentamos aqui um truque mágico que utiliza a decomposição na base 3 para transportar a carta desconhecida a posição escolhida, montando um "truque mágico" que certamente encantará a plateia, já apresentado em [8]. O truque requer apenas um pouco de prática mental de se escrever números pequenos na base 3 . Ao final, apresentamos uma generalização para qualquer base.
\end{abstract}

\section{A matemática de uma distribuição de cartas}

Tomemos um baralho de 27 cartas, viradas para baixo e vamos numerá-las sequencialmente de 0 a 26, de cima para baixo. Vamos distribuí-las em três montes em sequência. Veja a Figura 1. Os montes receberão as seguintes cartas:

$$
\begin{array}{ll}
1^{\circ} \text { monte: } & 0,3,6, \ldots, 3 q, \ldots, 24 ; \\
2^{\circ} \text { monte: } & 1,4,7, \ldots, 3 q+1, \ldots, 25 ; \\
3^{\circ} \text { monte: } & 2,5,8, \ldots, 3 q+2, \ldots, 26 .
\end{array}
$$



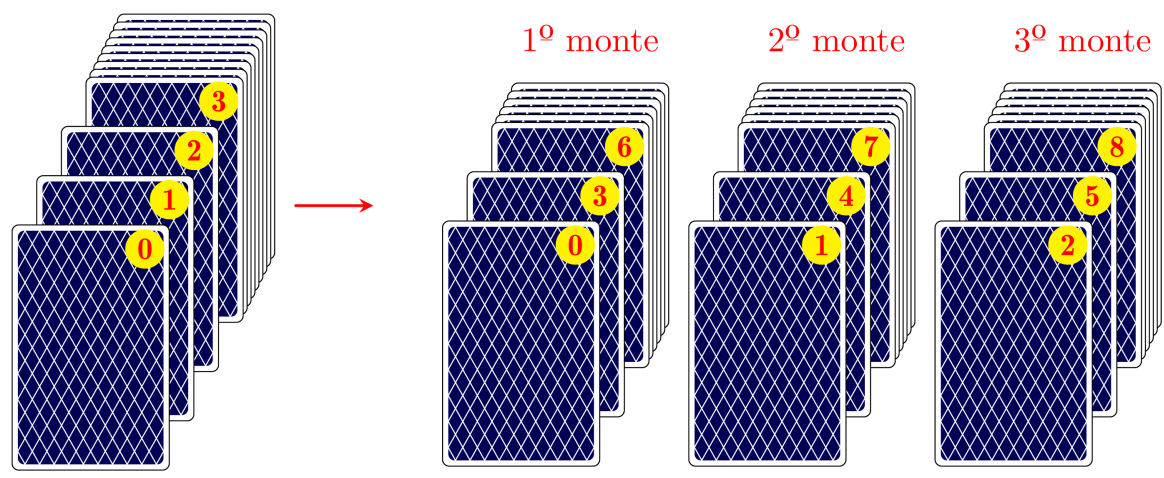

Figura 1: Distribuição das cartas em seus respectivos montes. Os montes recebem cartas com numeração da forma $3 q, 3 q+1$ e $3 q+2$, respectivamente.

Observe que, em cada monte, a carta $3 q$ + r passará a ocupar a numeração q (ao reiniciarmos a numeração em cada monte), isto é, o quociente da antiga numeração por 3 .

Escolha um dos montes e volte a empilhá-los. Se o monte escolhido ficar no topo, a carta originalmente na posição $3 q+r$ ficará na posição $q=0 \cdot 9+q$. Se o monte escolhido ficar no meio, como os montes têm nove cartas, a carta originalmente na posição $3 q+r$ ficará na posição $1 \cdot 9+q$. Se o monte escolhido for posto embaixo, a carta originalmente na posição $3 q+r$ ficará na posição $2 \cdot 9+q$. Assim, marcaremos as posições do monte escolhido com $p=0, p=1$ ou $p=2$ de acordo com o posicionamento no topo, no meio ou embaixo, respectivamente.

Vejamos como essa distribuição de cartas reordena os números das cartas escritos na base 3. Seja um número n entre 0 e 26 e escreva-o na base 3 , com dígitos a, b, c: $n=(a b c)_{3}$. A separação em montes coloca n na posição de seu quociente por três num dos montes:

$$
(a b c)_{3}=9 a+3 b+c \mapsto q=3 a+b=(0 a b)_{3} .
$$

Se o monte que contém essa carta for parar na posição p, soma-se $9 \mathrm{p}$ a $(0 \mathrm{ab})_{3}$ e o posicionamento na pilha final será (pab) 3 , ou seja:

$$
\begin{gathered}
\text { Uma distribuição que coloca o monte escolhido na po- } \\
\text { sição p, acrescenta p à esquerda e descarta o dígito final! } \\
(\mathrm{abc})_{3} \mapsto(\mathrm{pab})_{3}
\end{gathered}
$$

Recorde que a numeração das cartas começa em zero. Se desejarmos deslocar a carta que começa na numeração $n=(a b c)_{3}$ para a posição $m$, que corresponde à numeração $m-1=(x y z)_{3}$, basta repetir a distribuição três vezes, colocando o monte em que aparece a carta escolhida nas posições correspondendo à ordem inversa dos dígitos de $\mathrm{m}-1$, ou seja, z, y e x:

$$
\mathrm{n}=(\mathrm{abc})_{3} 7^{1^{\mathrm{a}}: \mathrm{z}} \rightarrow(\mathrm{zab})_{3} 7^{2^{\mathrm{a}}: \mathrm{y}} \rightarrow(\mathrm{yza})_{3} 7^{3^{\mathrm{a}}: \mathrm{x}} \rightarrow(\mathrm{xyz})_{3}=\mathrm{m}-1
$$

que corresponde à m-ésima posição do baralho, de cima para baixo. Isso explica o truque que descreveremos adiante. 


\section{Fazendo uma distribuição na prática}
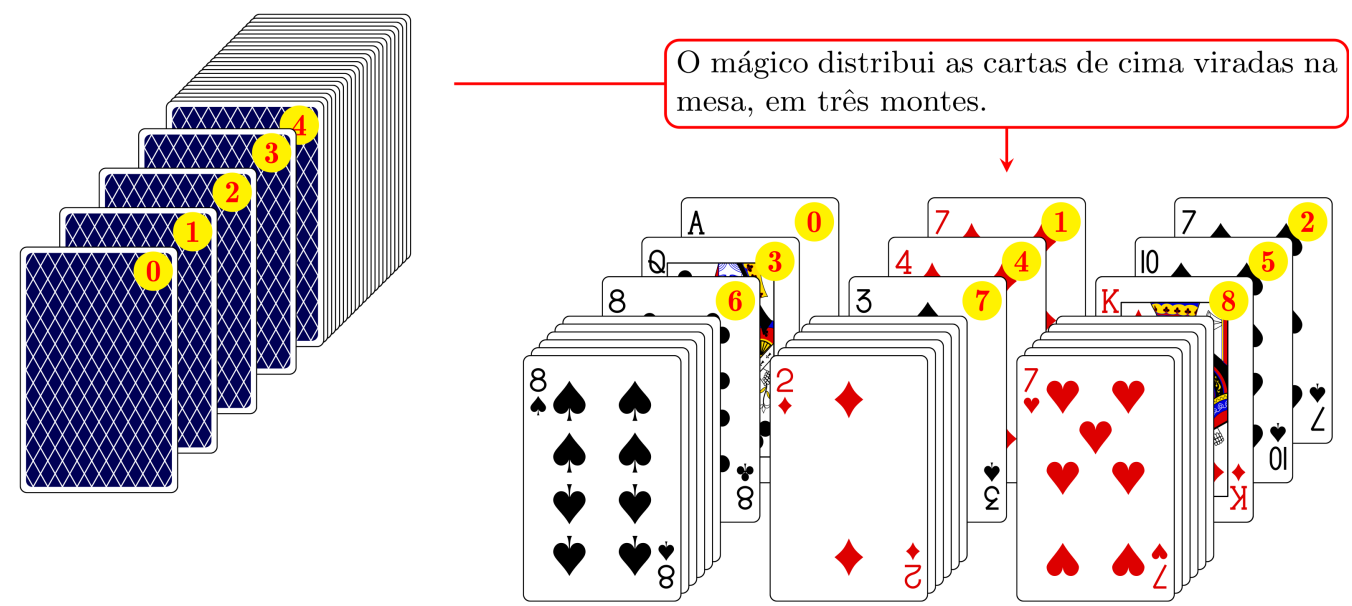

Informado de que o monte da carta escolhida é
o do meio, esse será posto na posição 0 , no topo,
quando as cartas forem viradas para baixo.
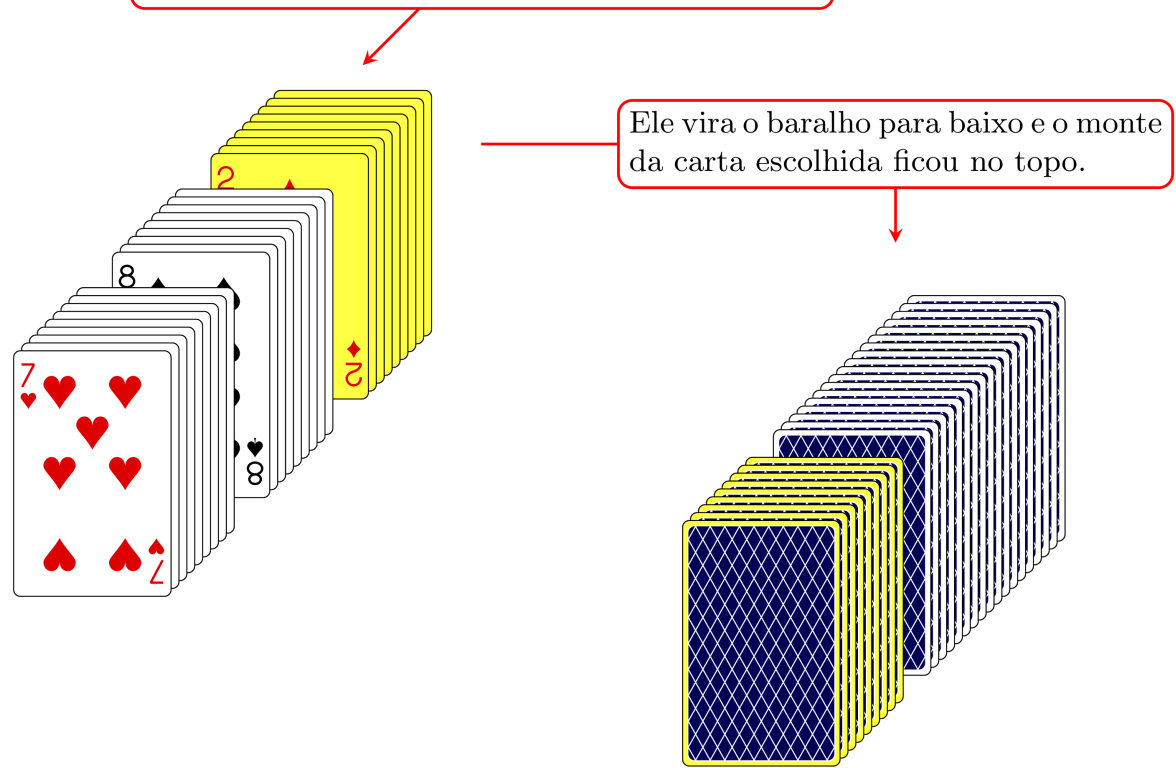

Figura 2: Uma distribuição para colocar o monte da carta escolhida na posição 0 = no topo. $\mathrm{O}$ participante informou que a carta escolhida está no monte do meio.

Para efetuar uma distribuição, com o baralho virado para baixo em suas mãos, o mágico deve retirar as cartas de cima e pô-las na mesa, empilhando-as nos três montes enquanto o participante observa, de forma que esse pode ver todas as cartas e apontar em que monte a carta que escolheu 
está. Além disso, a ordenação da numeração das cartas é mantida.

Ao final, tendo sido revelado o monte, o mágico deve lembrar-se que as posições $0=$ no topo, 1 = no meio e 2 = embaixo referem-se ao baralho virado para baixo quando for posicionar os montes com as cartas ainda sobre a mesa viradas para cima. Veja na Figura 2 a demonstração de uma distribuição.

\section{Decompondo um número na base 3 mentalmente}

É fácil decompor mentalmente números pequenos na base 3. Um bom método é pelos sucessivos restos da divisão por 3, sendo o próximo dividendo o quociente da primeira divisão. Com efeito, o resto por 3 é o quanto o dividendo excede um múltiplo de 3 que está na tabuada e o quociente é imediato dela. Esse método tem a vantagem de dar os dígitos na ordem para executar o truque. Por exemplo, para o número 17, 17 excede 15 em $\mathbf{2}, 15 \div 3=5$, e 5 excede 3 em $\mathbf{2}$, com quociente 1. Portanto, o truque deve ser feito com as posições 2,2 e $1\left(17=(122)_{3}\right)$.

\section{Execução do truque}

1. Selecione um participante da plateia. Mostre um baralho com 27 cartas e este deve escolher, em segredo, uma das cartas, podendo revelá-la à plateia. O baralho pode ser rapidamente embaralhado pelo próprio participante.

2. O mágico pergunta um número (que chamaremos aqui de $\mathrm{m}$ ) - digamos até 25 - a ele ou a outra pessoa da plateia. O número pode ser anotado numa lousa.

3. Mentalmente o mágico decompõe o antecessor $\mathrm{m}-1$ na base $3: \mathrm{m}-1=(\mathrm{xyz})_{3}$.

4. O mágico deve executar três distribuições como explicadas acima para as posições z, y e x, nessa ordem, perguntando ao participante ao final de cada distribuição em qual monte está a carta que escolheu.

5. Ao final das três distribuições, com o baralho em mãos virado para baixo, o mágico retira as cartas de cima uma a uma, contando de 1 a m, virando apenas a m-ésima carta, perguntando no ato se é esta a carta escolhida, o que o espantado participante confirmará.

A Figura 3 ilustra uma execução completa do truque.

\section{Uma generalização para $b^{k}$ cartas}

O truque pode estender-se para qualquer base. A base b é o número de montes, e, para um baralho de $\mathrm{b}^{\mathrm{k}}$ cartas, precisamos de $\mathrm{k}$ distribuições. O desafio é decompor números na base b mentalmente.

Um caso interessante é fazer o truque com $b^{2}$ cartas, com b montes e apenas duas distribuições, uma vez que decompor números de apenas dois dígitos na base b é uma questão de quociente e resto na divisão por b:

$$
0 \leqslant n<b^{2}: \quad n=b q+r, \quad 0 \leqslant r<b \Leftrightarrow n=(q r)_{b} .
$$

Como exercício, demonstre a generalização e aprenda também o truque com 16 ou 25 cartas e duas distribuições. 


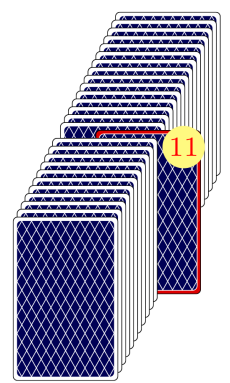

\section{$1^{\underline{a}}$ distribuição}

O participante informa que a carta está no $3^{\mathrm{O}}$ monte... que deve ser posto voltado para baixo na posição $\mathbf{0}=$ no topo.
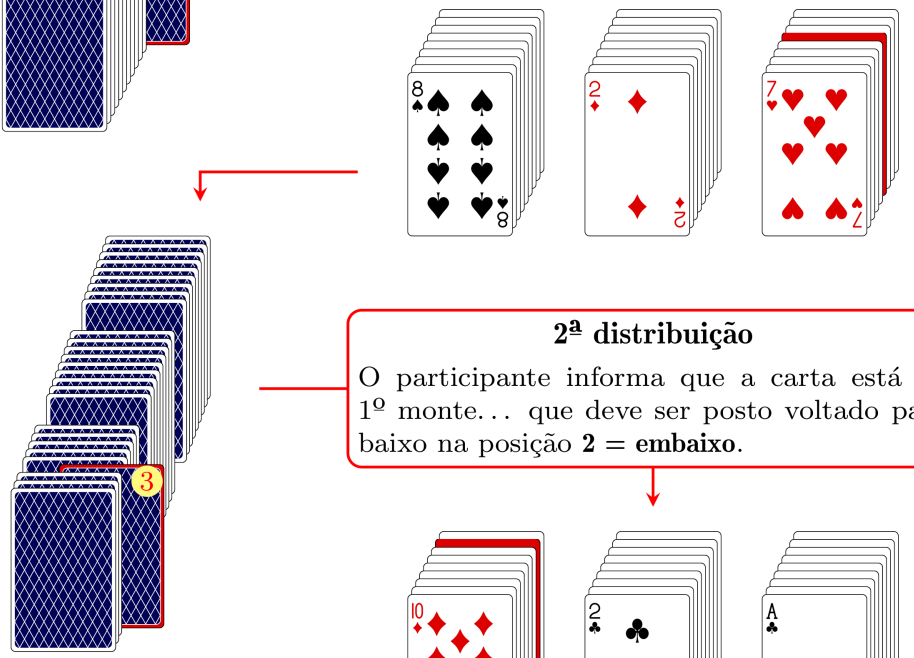

\section{$2^{\underline{a}}$ distribuição}

O participante informa que a carta está no $1^{\mathrm{O}}$ monte... que deve ser posto voltado para baixo na posição $\mathbf{2}=$ embaixo.
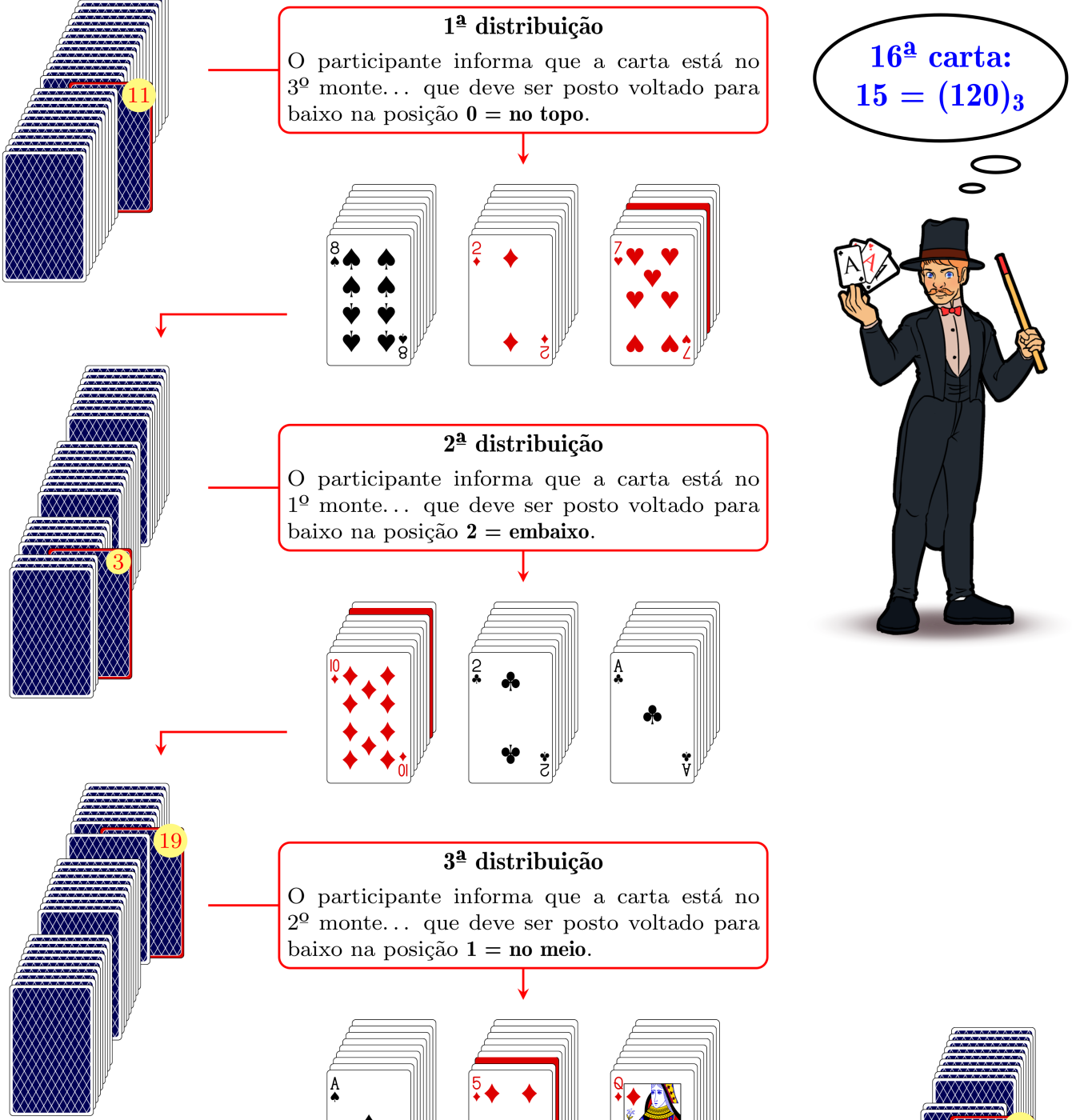

\section{$3^{\underline{a}}$ distribuição}

O participante informa que a carta está no $2^{\mathrm{O}}$ monte... que deve ser posto voltado para baixo na posição $\mathbf{1}=$ no meio.
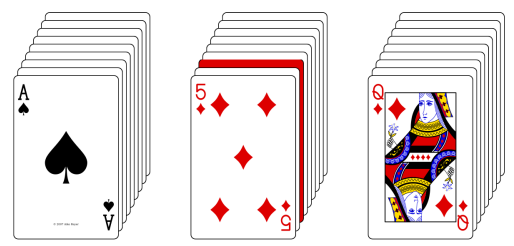

Pronto! A carta está na numeração 15 , ou seja, é a $16^{\mathbf{a}}$ carta. O mágico retira as cartas de cima e as põe sobre a mesa para baixo, contando-as de 1 a 15 , e vira a $16^{\mathrm{a}}$ carta. O participante confirma que é a carta escolhida.

Figura 3: Um exemplo do truque em sua totalidade. Supomos que foi escolhido o número 16. O mágico decompõe $15=(120)_{3}$ e deve fazer as distribuições para as posições 0,2 e 1 , nessa ordem. Supondo que a carta escolhida iniciou na posição $11=(102)_{3}$, as posições ocupadas por ela após cada distribuição serão $11=(102)_{3} 7^{1^{\mathrm{a}}:} \stackrel{0}{\rightarrow}(010)_{3}=37^{2^{\mathrm{a}}:} \stackrel{2}{\rightarrow}(201)_{3}=197^{3^{\mathrm{a}}}: \stackrel{1}{\rightarrow}(120)_{3}=15$. 


\section{Referências}

[1] CARVAlho, M. P. de; SANTOS, J. M. "Dinâmica de um truque de cartas." Boletim da Sociedade Portuguesa de Matemática, $\mathrm{n}^{\circ}$ 70, 2014.

[2] FIALHO, P. M. S. Matemática e Embaralhamento de Cartas: de Mágicas a Cadeias de Markov. Dissertação (Mestrado) — Universidade Federal de Minas Gerais, 2016.

[3] RODRIGUES, J. C. F. "Adivinhando o número pensado: uma contribuição para atividades em sala de aula." Educação Matemática em Revista, pp.152-165, 2017.

[4] SAMPAIO, J. C.; MALAGUTTI, P. L. Mágicas, matemática e outros mistérios. São Carlos: EdUFSCar, 2008.

[5] ALVES, A. G. Mágicas matemáticas como metodologia de ensino. Dissertação (ProfMat) Universidade Federal de São Carlos, São Carlos, 2015.

[6] SHENG L. Y.; FRASSON, M. V. S. "Uma mágica com cartas usando a base dois." Revista do Professor de Matemática, v. 99, 2019.

[7] MCOWAN, P.; PARKER, M. The manual of Mathematical Magic. [S.1.]: www. mathematicalmagic.com/, 2010.

[8] GARDNER, M. Mathematics, Magic and Mystery. Nova York: Dover, 1956.

Miguel V. S. Frasson

ICMC - Universidade de São Paulo

<frasson@icmc.usp.br>

Lee Y. Sheng

Universidade Federal do Mato Grosso

$<$ leeufmt@yahoo.com.br>

Recebido: 08/06/2020

Publicado: 28/08/2020 